\title{
BMJ Sedentary behaviours and obesity Open in adults: the Cardiovascular Risk in Young Finns Study
}

\author{
I Heinonen, ${ }^{1} \mathrm{H}$ Helajärvi, ${ }^{2} \mathrm{~K}$ Pahkala, ${ }^{1,2} \mathrm{O} \mathrm{J}$ Heinonen, ${ }^{2} \mathrm{M}$ Hirvensalo, ${ }^{3} \mathrm{~K}$ Pälve, ${ }^{1}$ \\ T Tammelin, ${ }^{4}$ X Yang, ${ }^{4}$ M Juonala, ${ }^{1,5}$ V Mikkilä, ${ }^{7}$ M Kähönen, ${ }^{8}$ T Lehtimäki, ${ }^{9}$ \\ J Viikari, ${ }^{5}$ O T Raitakari ${ }^{1,6}$
}

To cite: Heinonen I, Helajärvi $\mathrm{H}$, Pahkala $\mathrm{K}$, et al. Sedentary behaviours and obesity in adults: the Cardiovascular Risk in Young Finns Study. BMJ Open 2013;3:e002901.

doi:10.1136/bmjopen-2013002901

- Prepublication history and additional material for this paper are available online. To view these files please visit the journal online (http://dx.doi.org/10.1136/ bmjopen-2013-002901)

Received 18 March 2013 Revised 18 April 2013 Accepted 19 April 2013

This final article is available for use under the terms of the Creative Commons Attribution Non-Commercial 2.0 Licence; see http://bmjopen.bmj.com

For numbered affiliations see end of article.

\section{Correspondence to} Dr llkka Heinonen; ilkka.heinonen@utu.fi

\section{ABSTRACT}

Objective: Sedentary behaviour may contribute to the development of obesity. We investigated the relations between different types of sedentary behaviour and adiposity markers in a well-characterised adult population after controlling for a wide range of potential confounders.

Design: Cross-sectional study.

Setting: The Cardiovascular Risk in Young Finns Multicenter Study. Participants Sedentary time (TV viewing, computer time, reading, music/radio listening and other relaxation) was assessed with a questionnaire for 1084 women and 909 men aged 30-45 years. Other study variables included occupational and leisure-time physical activity, sleep duration, socioeconomic status, smoking, alcohol consumption, energy intake, adherence to the recommended diet, multiple individual food items, age and genetic variants associated with body mass index (BMI). Primary outcome measures BMI in $\mathrm{kg} / \mathrm{m}^{2}$ and waist circumference (WC in $\mathrm{cm}$ ).

Results: Of the different sedentary behaviour types, TV viewing was most consistently related to higher BMI and WC, both in men and women. One additional daily TV hour was associated with a $1.81 \pm 0.44 \mathrm{~cm}$ larger $W C$ in women and $2 \mathrm{~cm} \pm 0.44 \mathrm{~cm}$ in men (both $p<0.0001$ ). The association with TV was diluted, but remained highly significant after adjustments with all measured covariates, including several potentially obesogenic food items associated with TV viewing. The intakes of food items such as sausage, beer and soft drinks were directly associated with TV viewing, while the intakes of oat and barley, fish, and fruits and berries were associated indirectly. After these adjustments, non-TV sedentary behaviour remained associated with adiposity indices only in women.

Conclusions: Out of the different types of sedentary behaviour, TV viewing was most consistently associated with adiposity markers in adults. Partial dilution of these associations after adjustments for covariates suggests that the obesogenic effects of TV viewing are partly mediated by other lifestyle factors.

\section{ARTICLE SUMMARY}

\section{Article focus}

- Our aim was to study which types of sedentary behaviours are associated with obesity in adults after controlling for a wide range of potential confounders.

\section{Key messages}

- Of the different sedentary behaviour types, TV viewing is most consistently related with higher body mass index (BMI) and large waist circumference in both sexes.

- Partial dilution of the association between TV viewing and adiposity markers after adjustments for numerous covariates suggests that the obesogenic effects of TV viewing are partly mediated by other lifestyle factors, such as a non-prudent diet.

Strengths and limitations of this study

- The strength and novelty of our study is that we could take into consideration a wide range of confounders that could influence the relations between sedentary behaviour and adiposity. These include various types of physical activity, energy intake, detailed diet composition, alcohol consumption, smoking, socioeconomic status, sleep duration as well as novel genetic variants associated with increased BMI.

- The major limitation of the present study is that it is cross-sectional in design, meaning that it cannot address the causality of the findings.

\section{INTRODUCTION}

Obesity $^{1}$ and particularly central adiposity ${ }^{2}$ are risk factors contributing to the development of cardiometabolic diseases and increased mortality. Sedentary behaviour can be defined as an immobile state of the body (eg, sitting) resulting in energy expenditure close to the resting metabolic rate. ${ }^{3-5}$ Sedentary behaviour is known to be associated with obesity, independent of leisure-time physical exercise. ${ }^{6-11}$ This association may be due to immobility or other 
associated factors predisposing to obesity, such as dietary behaviour. ${ }^{12}$ In addition, sleep duration is associated with obesity, ${ }^{13-15}$ and sleep duration and sedentary behaviour may be linked. It has also been suggested that obese individuals might favour spending more time sitting and be physically less active because of their body weight and genetic predisposition. ${ }^{16}$

These behaviours and genetic factors may potentially confound the association of sedentary behaviour and obesity. Furthermore, the relations between sedentary behaviour and obesity may differ across different types of sedentary behaviour, that is, its subcategories. To further clarify the association between sedentary behaviour and adiposity, we studied leisure-time sedentary behaviour and its various subcategories, as well as their association with body mass index (BMI) and waist circumference (WC) in a large population of young and middle-aged Finnish adults. The independent cross-sectional association of sedentary behaviour was assessed by taking into account a wide range of potential confounders, including genetic predisposition for obesity, leisure-time physical activity, energy intake, adherence to the recommended diet and multiple other food items, sleep duration and other confounding risk factors for obesity (age, socioeconomic status, smoking, alcohol consumption, occupational physical workload and housework).

\section{METHODS}

\section{Participants}

The Cardiovascular Risk in Young Finns Study is an ongoing multicenter follow-up study of atherosclerosis risk factors. ${ }^{17}$ The first cross-sectional survey was conducted in 1980, when 3596 individuals aged 3-18 years participated. These participants were randomly chosen from the national registry of the study district. Since 1980, several follow-up studies have been conducted. The latest 27-year follow-up survey, which this study is based on, was performed in 2007 when 2204 (aged 30-45 years) of the original participants attended. Several drop-out analyses have been performed that have been described in detail by Raitakari et al, ${ }^{17}$ and based on these analyses, it can be said that this cohort and the surveys represent the general population fairly well. For this analysis, the sample comprised 1993 participants (1084 women and 909 men) who had a complete dataset including information on collected leisure-time sedentary behaviour subcategories, leisure time exercise and active commuting, and BMI and WC. The participants gave a written informed consent, and the study was approved by the local ethics committees.

\section{BMI and WC}

Weight was measured with a digital scale in light clothing without shoes with an accuracy of $0.1 \mathrm{~kg}$, and height with a wall-mounted stadiometer with $0.1 \mathrm{~cm}$ accuracy. BMI was calculated as weight $(\mathrm{kg}) /(\text { height }(\mathrm{m}))^{2}$. WC was measured with a measuring tape at the end of expiration at the mid-axillary line between the iliac crest and the lowest rib (accuracy of $0.1 \mathrm{~cm}$ ).

\section{Sedentary behaviour}

A self-administered questionnaire was used to collect data on various types of leisure-time sedentary behaviours. The participants were asked how many hours per day $(0,1,2,3, \ldots, 9$ and $\geq 10 \mathrm{~h}$ as options) they typically spent viewing TV, using the computer, reading, listening to music/radio, and in other type of relaxation. Total leisure-time sedentary time $(\mathrm{h} /$ day $)$ was calculated based on time spent in all the sedentary behaviour subcategories listed above, and non-TV sedentary time including all the other sedentary behaviour types except $\mathrm{TV}$ viewing. Screen time (h/day) was defined as the sum of the reported TV viewing and computer hours.

\section{Physical activity and its subcategories}

A self-administered questionnaire was used to assess leisure-time physical activity, including leisure-time physical exercise, active commuting and housework. In addition, the occupational physical workload was assessed. Data on leisure-time exercise and active commuting were combined to calculate a total metabolic equivalent (MET) index in MET $\mathrm{h} /$ week (hereafter, the MET index). One MET corresponds to an energy consumption of $1 \mathrm{kcal} /$ weight $\mathrm{kg} / \mathrm{h}$ during rest. For leisure-time physical exercise, data on frequency, duration and intensity were collected. ${ }^{18}$ Frequency was categorised as: (1) not at all, (2) once a month, (3) once a week, (4) 2-3 times a week, (5) 4-6 times a week and (6) daily. The average duration of a single bout of exercise was defined as: (1) <20 min, (2) 20-40 min, (3) 40-60 min and (4) $>60 \mathrm{~min}$. For exercise intensity, the categories were: (1) not getting out of breath or sweating, (2) getting out of breath and sweating slightly and (3) getting out of breath and sweating heavily. The MET $\mathrm{h} /$ week for active commuting to work were calculated based on the travel mode (cycling or walking) and length of the commuting distance. The MET index was estimated by multiplying the leisure-time exercise intensity, frequency and duration, and adding the MET $\mathrm{h} /$ week for active commuting. ${ }^{18}$ The range of the MET index was $0-163 \mathrm{MET} \mathrm{h} /$ week. The index has been validated against data collected with accelerometers and pedometers. ${ }^{18}$

The level of occupational physical workload was estimated as: (1) light sedentary work; (2) other sedentary work; (3) physically light work, performed mainly standing, or including light activity; (4) work including moderate physical activity; (5) physically strenuous work or (6) physically very strenuous work. The time spent in, for example, gardening and related housework $(\mathrm{h} / \mathrm{month})$ was classified as (1) light, (2) moderate and (3) strenuous activities.

\section{Diet, alcohol consumption, smoking, sleep duration and socioeconomic status}

Food consumption was assessed using a 131-item food frequency questionnaire (FFQ), developed and validated 
by the Finnish National Institute for Health and Welfare. ${ }^{19}$ The participants were asked to report the daily frequency and serving size of selected foods and dishes during the previous 12 months. The questionnaire additionally included open questions to enable reporting of foods not listed in the FFQ. The daily figures on specific food or food group consumptions and the nutrient intakes were calculated using the latest version of the National Food Composition Database, Fineli. ${ }^{20}$

In addition, a diet score describing each participant's adherence to the Nutrition Recommendations set by the National Nutrition Council ${ }^{21}$ as well as to the American Heart Association food guidelines ${ }^{22}$ and dietary guidelines for Americans ${ }^{23}$ was calculated. This score has been constructed particularly with regard to the risk of cardiometabolic diseases. Nine food groups in the score, which are unambiguously either to be preferred or avoided, have been chosen. Of these nine groups, whole grains, fish, fruits, vegetables and nuts are classified as favourable, whereas red and processed meats, sweets, sugar-sweetened beverages and fried potatoes are classified as unfavourable foods. The consumption of each of these food groups was categorised in sex-specific quartiles and assigned ascending values (0, 1, 2 and 3) for favourable foods and descending values $(3,2$, land 0 ) for unfavourable foods. Thus, the quality of diet was evaluated as a score ranging from 1 to 27 . For the purpose of this study, a wide range of individual dietary items (see online supplementary table S1) thought to represent the overall quality of diet providing information, for example, dietary carbohydrate contents were additionally selected for further analyses. Food items that were selected as possible confounding factors in multivariable models were chosen according to their correlation with TV time with either sex (see online supplementary tables S2 and S3). In addition, a fibre-sucrose intake ratio was calculated to describe the overall quality of carbohydrates in the diet.

Smoking habits were collected with a self-administered questionnaire. Individuals who reported smoking daily were considered as smokers. Similar results were obtained, if ever smoking (current/never/exsmoking) or pack-years were used as covariates in multivariable models (data not shown).

The participants were asked how many hours they usually slept per night (range from $<5$ to $>10 \mathrm{~h}$, scaling every $30 \mathrm{~min}$ ). Socioeconomic status was determined based on the reported occupation: (1) manual, (2) lower, non-manual and (3) upper, non-manual. Education and income were also evaluated, but their effects on results were similar to that of occupation. Employment status was evaluated based on a question asking whether the participant was unemployed at the time of the follow-up or not.

\section{Genetic variants}

A genome-wide analysis was performed with Illumina Bead Chip (Human 670K). Complete data were available for 1939 individuals. In these analyses, we used data on 31 single nucleotide polymorphisms (SNPs) that have recently been shown to be associated with BMI in a meta-analysis utilising data on 249796 individuals. ${ }^{24}$ A genetic obesity risk score was calculated as a weighted scale variable of risk alleles in these $31 \mathrm{SNPs} .{ }^{25}$

\section{Statistical analysis}

Sex differences for study variables were analysed with the non-parametric Wilcoxon two-sample test (table 1). The associations between sedentary behaviour and BMI, WC as well as risk factors for obesity were studied by calculating Spearman's correlation coefficients by sex (tables 2 and 3). Similar analyses were performed for physical activity (tables 2 and 3). These analyses were performed for the whole study population excluding the unemployed participants.

All types of sedentary behaviour and physical activity variables with an association with $\mathrm{BMI}$ and $\mathrm{WC}$ in univariate analyses were selected for subsequent multivariable linear regression analyses stratified by sex (tables 4 and 5). Other covariates included in these analyses represented potential confounders: genetic obesity risk score, energy intake and quality of diet (diet score), alcohol consumption, smoking, sleep duration and socioeconomic status (tables 4 and 5).

Linearity between all covariates and BMI and WC was evaluated visually using plot charts, as well as statistically, and covariates with significant non-linear association (energy intake, diet score and sleep duration) were included in multivariate analyses as their quadratic terms.

To test how much various covariates influenced the association between sedentary behaviour and WC, a four-step multivariable linear regression analysis was made. An increasing number of covariates were added to a simple age-adjusted multivariable linear regression model stratified by sex (model 1) as follows (figure 1): obesity gene variants and lifestyle factors other than diet (model 2); obesity gene variants and lifestyle factors, diet score and energy intake (model 3); obesity gene variants and lifestyle factors, energy intake and all dietary items that are associated with TV viewing in either sex (see online supplementary tables S2 and S3; model 4).

To evaluate how much TV viewing time and non-TV sedentary time increased the risk of obesity, we calculated (using generalised linear modelling) additionally age-adjusted, sex-adjusted and other obesity covariateadjusted relative risks (RRs) for an obesity outcome variable defined by sex-specific WC cut-off points $(>88 \mathrm{~cm}$ in women and $>102 \mathrm{~cm}$ in men). The other covariates were genetic obesity risk score, energy intake, diet score and dietary items that are associated with TV viewing, alcohol consumption, physical activity, smoking, sleep duration and socioeconomic status. Similar analyses were made for non-TV sedentary time.

Since TV viewing time was associated with WC in both the sexes, it was selected for further age-adjusted and 
Table 1 Baseline characteristics

\begin{tabular}{|c|c|c|c|c|c|}
\hline \multirow[b]{2}{*}{ Variable } & \multicolumn{2}{|c|}{ Women $n=1084$} & \multicolumn{2}{|c|}{ Men $\mathrm{n}=909$} & \multirow[b]{2}{*}{ p Value } \\
\hline & Mean & SD & Mean & SD & \\
\hline Age (years) & 37.7 & 4.9 & 37.5 & 5.1 & 0.36 \\
\hline Body mass index $\left(\mathrm{kg} / \mathrm{m}^{2}\right)$ & 25.3 & 4.9 & 26.7 & 4.2 & $<0.0001$ \\
\hline Waist circumference (cm) & 83.6 & 12.4 & 94.2 & 11.8 & $<0.0001$ \\
\hline \multicolumn{6}{|l|}{ Sedentary behaviour } \\
\hline Total sedentary time (h/day) ${ }^{*}$ & 5.2 & 3.0 & 5.5 & 2.8 & $<0.0001$ \\
\hline Screen time $(\mathrm{h} /$ day $) \dagger$ & 2.7 & 1.8 & 3.1 & 1.8 & $<0.0001$ \\
\hline TV viewing (h/day) & 1.7 & 1.1 & 1.9 & 1.1 & 0.0009 \\
\hline Computer use (h/day) & 1.0 & 1.3 & 1.2 & 1.4 & $<0.0001$ \\
\hline Reading (h/day) & 1.1 & 0.8 & 0.8 & 0.6 & $<0.0001$ \\
\hline Relaxation (h/day) & 1.1 & 1.1 & 1.2 & 1.1 & 0.007 \\
\hline Radio/music listening (h/day) & 0.3 & 0.8 & 0.4 & 0.7 & $<0.0001$ \\
\hline \multicolumn{6}{|l|}{ Physical activity } \\
\hline Total MET index(MET h/week) & 19.6 & 20.5 & 19.9 & 22.0 & 0.15 \\
\hline Leisure-time exercise (MET h/week) & 13.5 & 14.2 & 15.8 & 17.6 & 0.53 \\
\hline Active commuting (MET h/week) & 6.1 & 12.4 & 4.0 & 11.1 & $<0.0001$ \\
\hline Light gardening and other housework (h/month) & 25.0 & 21.5 & 11.2 & 13.1 & $<0.0001$ \\
\hline Moderate gardening and other housework (h/month) & 10.4 & 11.9 & 6.4 & 7.4 & $<0.0001$ \\
\hline Strenuous gardening and other housework (h/month) & 5.7 & 10.1 & 7.1 & 12.6 & 0.14 \\
\hline Occupational physical workload (scale, 1-6) & 3.3 & 1.5 & 3.8 & 1.6 & $<0.0001$ \\
\hline \multicolumn{6}{|l|}{ Covariates } \\
\hline Energy intake (kcal/day) & 2168 & 678 & 2675 & 852 & $<0.0001$ \\
\hline Diet score (points, scale 1-27) & 15.1 & 3.7 & 11.8 & 3.7 & $<0.0001$ \\
\hline Alcohol consumption (drinks/day) & 0.6 & 0.7 & 1.4 & 1.9 & $<0.0001$ \\
\hline Sleep duration (h/day) & 7.5 & 1.6 & 7.3 & 1.6 & $<0.0001$ \\
\hline Socioeconomic status (scale, $1-3$ ) & 2.2 & 0.9 & 2.0 & 0.9 & $<0.0001$ \\
\hline Daily smoking (\%) & 15 & & 23 & & $<0.0001$ \\
\hline \multicolumn{6}{|c|}{$\begin{array}{l}\text { Values are mean and SD. } \\
\text { MET index=leisure-time exercise+active commuting. } \\
\text { p Value (non-parametric Kruskal-Wallis test). } \\
{ }^{*} \text { TV viewing+computer use+reading+music/radio+other relaxation hours. } \\
\text { †TV viewing+computer use. } \\
\text { MET, metabolic equivalent; diet score, adherence to the recommended diet. }\end{array}$} \\
\hline
\end{tabular}

sex-adjusted pooled analyses to investigate the relations between TV time and adiposity markers at various MET index levels. For these analyses, the participants were divided into four groups based on daily TV viewing time $(<1,>1$ and $<2,>2$ and $<3$, and $>3 \mathrm{~h}$; figure 2$)$. These cut-off points were selected to provide practically useful categories. The participants were also divided into three sex-specific MET index groups. In the low activity group, MET index was <5 MET $\mathrm{h}$ /week both in men and women. In the high MET index group, MET index was $>22.8 \mathrm{MET} \mathrm{h} /$ week in men and >20.7 MET $\mathrm{h} /$ week in women. These limits were set to obtain adequate participant numbers in each group and to have practically meaningful MET limits for physically inactive, moderately active and highly active men and women. Within each MET index group, the age-adjusted and sexadjusted association between TV viewing time and obesity markers was examined by calculating Spearman's correlation coefficients.

All statistical analyses were performed using SAS V.9.2, and statistical significance was inferred at a two-tailed $\mathrm{p}<0.05$.

\section{RESULTS}

The characteristics of the study population are shown in table 1 . Overall, men were more sedentary than women, except for reading. In both sexes, slightly less than $2 \mathrm{~h} /$ day was spent viewing TV and an average of $1 \mathrm{~h}$ /day in each of the other leisure-time sedentary behaviours. Men spent more time in leisure-time exercise, whereas women were more active in light and moderate gardening/household work and active commuting (table 1).

In univariate correlation analyses (women, table 2 and men, table 3), total sedentary time, TV viewing time, screen time and other relaxation were directly associated with WC and BMI in both sexes $(\mathrm{p}<0.05)$. In women, computer time and listening to radio/music were also directly associated with WC and BMI $(\mathrm{p}<0.05$ in both). In both sexes, total sedentary time was directly associated with alcohol consumption and smoking, but not with energy intake. The genetic obesity risk score for high BMI was also directly associated with sedentary time in men.

No association between total sedentary behaviour and the MET index was detected $(\mathrm{r}=0.02, \mathrm{p}=0.49$ in men and 


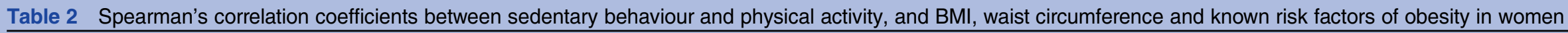

\begin{tabular}{|c|c|c|c|c|c|c|c|c|c|c|}
\hline & BMI & WC & $\begin{array}{l}\text { Energy } \\
\text { intake }\end{array}$ & $\begin{array}{l}\text { Diet } \\
\text { score }\end{array}$ & $\begin{array}{l}\text { Alcohol } \\
\text { consumption }\end{array}$ & $\begin{array}{l}\text { Socioeconomic } \\
\text { status }\end{array}$ & Smoking & $\begin{array}{l}\text { Sleep } \\
\text { duration }\end{array}$ & Age & $\begin{array}{l}\text { Genetic } \\
\text { obesity risk } \\
\text { score }\end{array}$ \\
\hline \multicolumn{11}{|l|}{ Sedentary behaviour } \\
\hline Total sitting (h/day)* & $0.19^{\star \star \star}$ & $0.17^{\star \star \star}$ & 0.04 & -0.01 & $0.08^{*}$ & $-0.16^{\star \star \star}$ & $0.16^{\star \star *}$ & -0.03 & 0.03 & -0.04 \\
\hline Screen time (h/day) $\dagger$ & $0.22^{\star \star \star}$ & $0.21^{\star \star \star}$ & 0.03 & $-0.07^{\star}$ & $0.10^{\star \star}$ & $-0.14^{\star \star \star}$ & $0.16^{\star \star *}$ & -0.08 & -0.03 & -0.04 \\
\hline TV viewing (h/day) & $0.19^{\star * *}$ & $0.18^{\star * *}$ & 0.02 & $-0.08^{*}$ & $0.12^{\star \star \star}$ & $-0.15^{\star \star \star}$ & $0.16^{\star * \star}$ & $-0.09^{\star *}$ & 0.03 & -0.05 \\
\hline Computer use (h/day) & $0.13^{\star \star *}$ & $0.12^{\star \star \star}$ & 0.03 & -0.02 & 0.01 & -0.03 & 0.04 & -0.03 & $-0.10^{\star \star \star}$ & 0.02 \\
\hline Reading (h/day) & 0.01 & 0.01 & 0.02 & $0.08^{\star *}$ & -0.03 & -0.01 & 0.01 & -0.01 & $0.09^{\star *}$ & -0.01 \\
\hline Other relaxation (h/day) & $0.09^{* \star}$ & $0.07^{\star}$ & $0.07^{\star}$ & -0.01 & 0.02 & $-0.17^{\star \star \star}$ & $0.12^{\star \star \star}$ & 0.03 & 0.06 & -0.01 \\
\hline Listening to radio/music (h/day) & $0.09^{\star *}$ & $0.07^{*}$ & $0.07^{*}$ & 0.05 & 0.04 & $-0.07^{\star}$ & 0.02 & 0.03 & $0.06^{\star}$ & 0.02 \\
\hline \multicolumn{11}{|l|}{ Physical activity } \\
\hline Total MET index (MET h/week) & $-0.08^{\star \star}$ & $-0.12^{\star \star \star}$ & 0.05 & $0.30^{\star \star *}$ & 0.01 & $0.09^{\star \star}$ & $-0.10^{\star *}$ & 0.02 & 0.02 & -0.00 \\
\hline Leisure-time exercise (MET h/week) & $-0.08^{\star \star}$ & $-0.13^{\star \star \star}$ & 0.04 & $0.29^{* * *}$ & 0.02 & $0.12^{\star \star \star}$ & $-0.14^{\star \star *}$ & -0.01 & 0.01 & 0.01 \\
\hline Active commuting (MET h/week) & -0.05 & -0.06 & 0.03 & $0.13^{* * *}$ & -0.01 & -0.03 & 0.01 & 0.03 & -0.01 & -0.02 \\
\hline $\begin{array}{l}\text { Light gardening and related } \\
\text { housework (h/month) }\end{array}$ & 0.00 & 0.03 & $0.10^{* *}$ & -0.01 & $-0.08^{\star *}$ & -0.02 & -0.02 & -0.01 & 0.05 & 0.01 \\
\hline $\begin{array}{l}\text { Moderate gardening and related } \\
\text { housework (h/month) }\end{array}$ & 0.05 & 0.06 & $0.09^{* *}$ & -0.01 & $-0.08^{\star *}$ & $-0.08^{\star}$ & 0.06 & -0.02 & 0.06 & 0.02 \\
\hline $\begin{array}{l}\text { Strenuous gardening and related } \\
\text { housework ( } \mathrm{h} / \text { month) }\end{array}$ & $0.08^{*}$ & $0.08^{*}$ & $0.15^{\star \star \star}$ & -0.04 & $-0.07^{\star}$ & $-0.14^{\star \star \star}$ & $0.07^{*}$ & -0.01 & $0.08^{*}$ & 0.03 \\
\hline $\begin{array}{l}\text { Occupational physical workload } \\
\text { (scale 1-6) }\end{array}$ & $0.08^{\star *}$ & $0.07^{*}$ & $0.08^{*}$ & $-0.09^{* *}$ & -0.02 & $-0.41^{\star \star \star}$ & $0.08^{* *}$ & -0.01 & 0.03 & -0.01 \\
\hline \multicolumn{11}{|c|}{$\begin{array}{l}{ }^{*} \mathrm{p}<0.05 . \\
{ }^{* \star} \mathrm{p}<0.01 . \\
{ }^{* \star *} \mathrm{p}<<0.001 \text {. } \\
\text { MET index=leisure-time exercise+active commuting. } \\
{ }^{\star} \mathrm{TV} \text { viewing+computer use+reading+listening to radio/music+other relaxation. } \\
\text { †TV viewing+computer use. }\end{array}$} \\
\hline
\end{tabular}


Table 3 Spearman's correlation coefficients between sedentary behaviour and physical activity, and BMI, waist circumference, and known risk factors of obesity in men

\begin{tabular}{|c|c|c|c|c|c|c|c|c|c|c|}
\hline & BMI & WC & $\begin{array}{l}\text { Energy } \\
\text { intake }\end{array}$ & $\begin{array}{l}\text { Diet } \\
\text { score }\end{array}$ & $\begin{array}{l}\text { Alcohol } \\
\text { consumption }\end{array}$ & $\begin{array}{l}\text { Socioeconomic } \\
\text { status }\end{array}$ & Smoking & $\begin{array}{l}\text { Sleep } \\
\text { duration }\end{array}$ & Age & $\begin{array}{l}\text { Genetic } \\
\text { obesity risk } \\
\text { score }\end{array}$ \\
\hline \multicolumn{11}{|l|}{ Sedentary behaviour } \\
\hline Total sedentary time $(\mathrm{h} / \text { day })^{\star}$ & $0.115^{\star \star *}$ & $0.14^{\star \star \star}$ & 0.003 & 0.02 & $0.07^{\star}$ & -0.04 & $0.08^{*}$ & 0.02 & 0.00 & $0.08^{*}$ \\
\hline Screen time (h/day) $\dagger$ & $0.13^{* * *}$ & $0.11^{\star \star \star}$ & -0.01 & -0.04 & $0.09^{* *}$ & 0.00 & 0.05 & -0.04 & $-0.09^{*}$ & $0.07^{*}$ \\
\hline TV viewing (h/day) & $0.20^{\star \star \star}$ & $0.21^{\star \star \star}$ & -0.00 & $-0.08^{\star}$ & $0.12^{\star \star \star}$ & $-0.10^{\star \star}$ & $0.11^{* * *}$ & -0.05 & 0.03 & 0.00 \\
\hline Computer use (h/day) & 0.01 & -0.03 & -0.01 & 0.02 & 0.00 & $0.12^{\star \star \star}$ & $-0.07^{*}$ & 0.00 & $-0.16^{\star \star \star}$ & $0.09^{\star \star}$ \\
\hline Reading (h/day) & 0.02 & 0.04 & $0.09^{\star \star}$ & $0.20^{\star \star \star}$ & -0.06 & $0.11^{\star \star \star}$ & -0.06 & 0.06 & $0.08^{\star}$ & 0.01 \\
\hline Other relaxation (h/day) & $0.14^{\star \star \star}$ & $0.12^{\star \star \star}$ & -0.03 & -0.02 & 0.03 & $-0.16^{\star \star \star}$ & $0.10^{\star *}$ & 0.03 & $0.09^{*}$ & 0.03 \\
\hline Listening to radio/music (h/day) & 0.05 & 0.04 & 0.07 & 0.05 & 0.02 & $-0.11^{\star \star}$ & $0.07^{*}$ & 0.02 & 0.03 & 0.04 \\
\hline \multicolumn{11}{|l|}{ Physical activity } \\
\hline Total MET index (MET h/week) & -0.05 & $-0.12^{\star \star \star}$ & $0.09^{\star}$ & $0.26^{\star * *}$ & -0.03 & $0.21^{\star \star *}$ & $-0.22^{\star \star *}$ & $0.10^{\star \star}$ & -0.00 & -0.02 \\
\hline Leisure-time exercise (MET h/week) & -0.03 & $-0.11^{\star \star \star}$ & $0.08^{*}$ & $0.21^{\star \star \star}$ & -0.00 & $0.23^{\star \star \star}$ & $-0.23^{\star * *}$ & $0.11^{\star \star \star}$ & -0.01 & -0.02 \\
\hline Active commuting (MET h/week) & $-0.07^{*}$ & $-0.10^{\star \star}$ & 0.07 & $0.21^{\star \star \star *}$ & -0.04 & 0.03 & -0.06 & -0.00 & -0.00 & 0.01 \\
\hline $\begin{array}{l}\text { Light gardening and related housework } \\
\text { activity (h/month) }\end{array}$ & -0.03 & -0.03 & 0.05 & $0.14^{\star \star \star}$ & 0.02 & 0.03 & -0.01 & 0.04 & -0.02 & 0.03 \\
\hline $\begin{array}{l}\text { Moderate gardening and related } \\
\text { (h/month) }\end{array}$ & -0.00 & -0.00 & $0.14^{\star \star *}$ & 0.03 & -0.03 & -0.01 & 0.033 & -0.05 & 0.02 & 0.01 \\
\hline $\begin{array}{l}\text { Strenuous gardening and related } \\
\text { (h/month) }\end{array}$ & 0.01 & 0.01 & $0.17^{\star \star \star}$ & $-0.08^{*}$ & 0.02 & $-0.12^{\star * \star}$ & $0.11^{* *}$ & -0.04 & $0.09^{\star *}$ & 0.00 \\
\hline $\begin{array}{l}\text { Occupational physical workload } \\
\text { (scale 1-6) }\end{array}$ & 0.05 & 0.02 & $0.13^{\star \star \star}$ & $-0.14^{\star \star \star}$ & 0.02 & $-0.64^{\star \star \star}$ & $0.17^{\star \star \star}$ & $-0.13^{\star \star \star}$ & $0.08^{*}$ & 0.06 \\
\hline
\end{tabular}

\section{${ }^{*} p<0.05$.}

${ }^{* *} p<0.01$.

$* * * 0.001$.

MET index=leisure-time exercise+active commuting

*TV viewing+computer use+reading+listening to radio/music+other relaxation.

†TV viewing+computer use.

BMI, body mass index; MET, metabolic equivalent; diet score, adherence to the recommended diet; WC, waist circumference. 
$\mathrm{r}=0.004, \mathrm{p}=0.89$ in women). In women, both the MET index and leisure-time exercise alone were inversely associated with BMI and WC, while strenuous gardening and housework and physical workload showed a direct association. In men, the MET index and its subcategories, leisure-time exercise and active commuting, were inversely associated with WC. In men, active commuting was the only physical activity subcategory associated with BMI (inverse association).

Multivariable models were applied to test the independent role of different types of sedentary behaviour on WC and BMI (tables 4 and 5). TV viewing time was directly associated with WC (tables 4 and 5) in both sexes, independent of the genetic obesity risk score, sleep duration, physical activity, energy intake and other covariates $(\mathrm{p}<0.002)$. One additional hour of TV viewing per day was associated with $1.8 \pm 0.4$ and $2 \pm 0.4 \mathrm{~cm}$ greater $\mathrm{WC}$ in women and men, respectively. Essentially similar results were seen when BMI was used instead of $\mathrm{WC}$, and the exclusion of unemployed participants from these analyses did not change the results either (data not shown).

To further elucidate the possibly independent role of TV viewing and non-TV sedentary time contributing to body adiposity, stepwise multivariable models were analysed (figure 1). For this purpose, we first selected all dietary items that were associated with TV viewing, and other types of sedentary behaviour as potential confounders. This was performed because the correlation between diet score and TV viewing (tables 2 and 3) indicated that part of the association between $\mathrm{WC}$ and $\mathrm{TV}$ viewing could be mediated by the quality of diet. Of the different sedentary behaviour subcategories, TV viewing was associated most consistently with food items that are considered non-prudent (see online supplementary tables S2 and S3). The intake of food items associated positively with TV viewing most consistently in both sexes included sausage, beer and soft drinks. On the other hand, the intake of oats and barley (mostly reflecting the habitual intake of porridge in the Finnish diet), fish, and fruits and berries was associated negatively with TV viewing. In stepwise multivariable analyses (figure 1), the change in WC for one additional TV viewing hour was only moderately attenuated when other covariates were added to an age-adjusted multivariable model by sex. When non-TV sedentary time was adjusted for other covariates, it remained statistically significantly associated with WC only in women (figure 1), but the magnitude for the same amount of time (ie, per hour) was far smaller than for TV time.

Both TV viewing time and non-TV sedentary time were associated with increased risk of abdominal obesity defined by large WC (table 6). For example, TV viewing $>3 \mathrm{~h} /$ day was associated with a nearly twofold increased risk of abdominal obesity compared with TV viewing $<1 \mathrm{~h} /$ day. The risk of obesity associated with TV viewing was slightly reduced in a fully adjusted model, but remained significant. Similarly, the risk of obesity associated with non-TV sedentary time remained significant in the adjusted model, but rendered non-significant after further adjustment with TV viewing (data not shown).

Table 4 Multivariable model for WC in women (includes all sedentary and physical activity categories that correlated with WC, as well as all established main confounders)

\begin{tabular}{|c|c|c|c|c|}
\hline Model $\left(R^{2}=0.14\right)$ & $\boldsymbol{\beta}$ & SE & $\mathbf{R}^{2}$ & p Value \\
\hline Age (years) & 0.39 & 0.09 & 0.027 & $<0.001$ \\
\hline Genetic obesity risk score (range 16.1-39.8) & 2.2 & 0.83 & 0.010 & 0.01 \\
\hline TV viewing (h/day) & 1.81 & 0.44 & 0.022 & $<0.001$ \\
\hline Computer use (h/day) & 1.00 & 0.33 & 0.012 & $<0.01$ \\
\hline Other relaxation (h/day) & -0.02 & 0.47 & 0.0001 & 0.96 \\
\hline Listening to radio/music (h/day) & -0.05 & 0.62 & 0.0001 & 0.93 \\
\hline Leisure-time exercise (MET h/week) & -0.11 & 0.03 & 0.019 & $<0.01$ \\
\hline Strenuous gardening and related housework (h/month) & -0.01 & 0.04 & 0.0001 & 0.90 \\
\hline Occupational physical workload (scale 1-6) & 0.61 & 0.34 & 0.004 & 0.07 \\
\hline Energy intake (100 kcal/day) & -0.007 & 0.02 & 0.0002 & 0.72 \\
\hline Energy intake*energy intake & 0.00004 & 0.00003 & 0.002 & 0.19 \\
\hline Diet score (scale, range $1-27$ ) & 0.48 & 0.70 & 0.0006 & 0.49 \\
\hline Diet score*diet score & -0.02 & 0.02 & 0.0008 & 0.45 \\
\hline Sleep duration (scale, range 1-10) & -2.53 & 1.38 & 0.005 & 0.07 \\
\hline Sleep duration*sleep duration & 0.20 & 0.13 & 0.003 & 0.13 \\
\hline Socioeconomic status (scale, 1-3) & -0.93 & 0.56 & 0.004 & 0.09 \\
\hline Alcohol (drinks/day) & 0.14 & 0.58 & 0.0001 & 0.80 \\
\hline Smoking (no/yes) & 0.02 & 1.25 & 0.0001 & 0.98 \\
\hline
\end{tabular}

$\beta=$ increase in WC caused by a one unit increase in the measured parameter.

$\mathrm{R}^{2}=$ per cent that model or measured parameter accounts for the variance of WC.

MET index=leisure-time exercise+active commuting.

*The increase in $\beta$ with one unit increase in energy intake, diet score and sleep duration is expressed in their quadratic terms, since these variables had a significant U-shaped relation with BMI and WC.

$\mathrm{BMI}$, body mass index; MET, metabolic equivalent; diet score, adherence to the recommended diet; WC, waist circumference. 
Table 5 Multivariable model for WC in men (includes all sedentary and physical activity categories that correlated with WC, as well as all established main confounders)

\begin{tabular}{|c|c|c|c|c|}
\hline Model $\left(R^{2}=0.13\right)$ & $\boldsymbol{\beta}$ & SE & $\mathbf{R}^{2}$ & p Value \\
\hline Age (years) & 0.40 & 0.08 & 0.034 & $<0.001$ \\
\hline Genetic obesity risk score (range 16.1-39.8) & 2.89 & 0.81 & 0.019 & $<0.01$ \\
\hline TV time (h/day) & 2.00 & 0.44 & 0.030 & $<0.001$ \\
\hline Other relaxation (h/day) & 0.64 & 0.41 & 0.004 & 0.11 \\
\hline Leisure-time exercise (MET h/week) & -0.07 & 0.03 & 0.012 & $<0.01$ \\
\hline Active commuting (MET h/week) & -0.009 & 0.04 & 0.0001 & 0.79 \\
\hline Energy intake (100 kcal/day) & -0.03 & 0.02 & 0.003 & 0.15 \\
\hline Energy intake*energy intake & 0.00005 & 0.00003 & 0.004 & 0.10 \\
\hline Diet score (scale, range 1-27) & 0.85 & 0.56 & 0.002 & 0.13 \\
\hline Diet score ${ }^{*}$ diet score & -0.05 & 0.02 & 0.007 & 0.03 \\
\hline Sleep duration (scale, range 1-10) & -0.30 & 1.22 & 0.0001 & 0.80 \\
\hline Sleep duration*sleep duration & 0.04 & 0.13 & 0.0001 & 0.79 \\
\hline Socioeconomic status (scale, $1-3$ ) & 0.183 & 0.48 & 0.0002 & 0.70 \\
\hline Alcohol (drinks/day) & 0.48 & 0.22 & 0.007 & 0.03 \\
\hline Smoking (no/yes) & -2.55 & 1.07 & 0.009 & 0.02 \\
\hline
\end{tabular}

$\beta=$ increase in WC caused by a one unit increase in the measured parameter.

$\mathrm{R}^{2}=$ per cent that model or measured parameter accounts for the variance of WC.

MET index=leisure-time exercise+active commuting.

${ }^{*}$ The increase in $\beta$ with the one unit increase in energy intake, diet score and sleep duration is expressed in their quadratic terms, since these variables had a significant $U$-shaped relation with BMI and WC.

BMI, body mass index; MET, metabolic equivalent; diet score, adherence to the recommended diet; WC, waist circumference.

Finally, we examined whether the association between TV viewing and WC was similar across the three physical activity categories (tertiles of the MET index; figure 2).
TV viewing was directly associated with WC (figure 2) in every MET index subcategory ( $\mathrm{p}$ for trend $<0.0001$ in all). In the low activity group, WC was on average $7 \mathrm{~cm}$

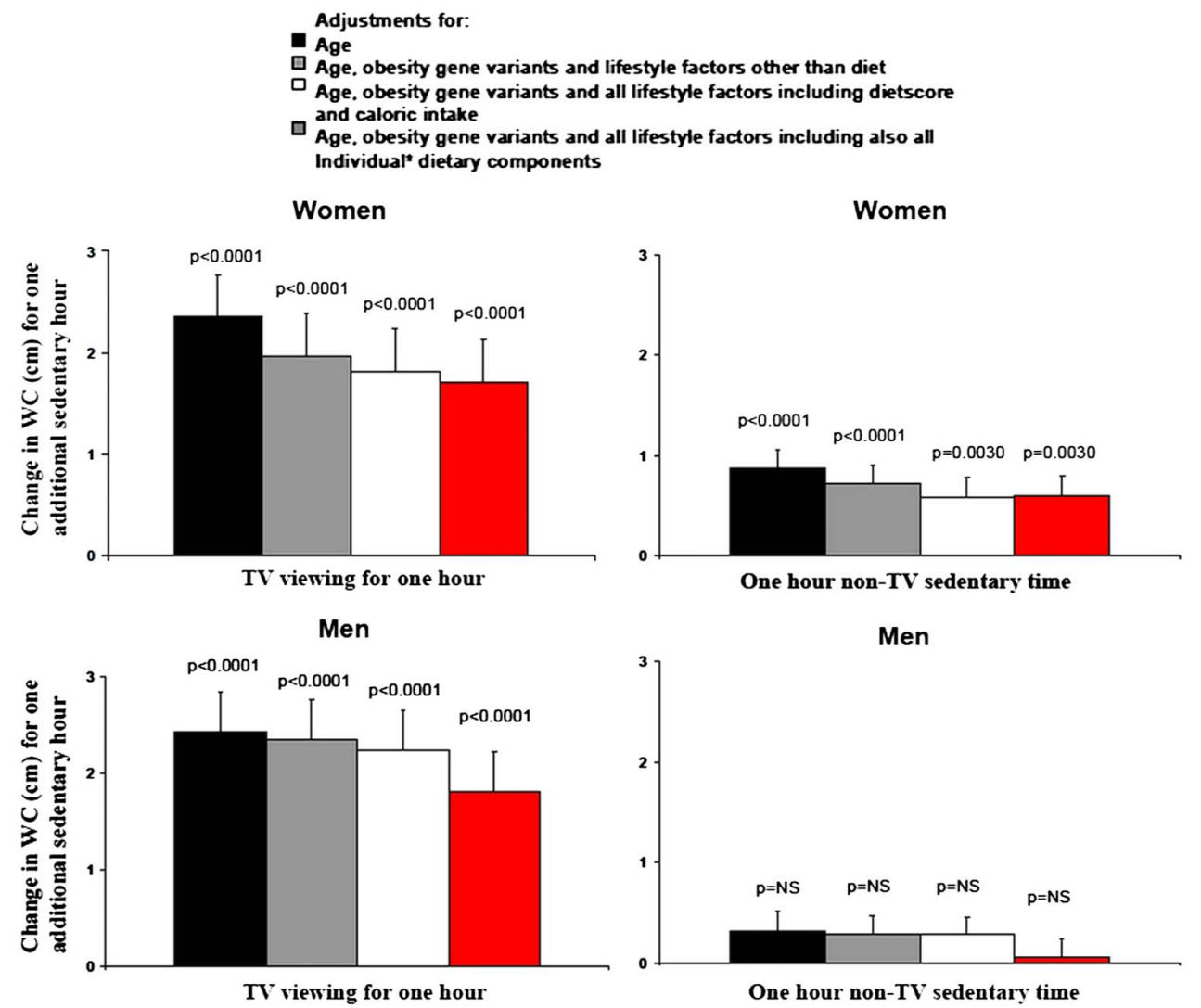

Figure 1 The associations of TV viewing time and non-TV sedentary time and waist circumference (WC) in different multivariable models in women ( $\mathrm{N}=784$ in all models) and men ( $\mathrm{N}=675$ in all models). ${ }^{*}$ With significant associations to TV viewing in either sex (see online supplementary tables S2 and S3). 
Figure 2 Age-adjusted and sex-adjusted waist circumference according to TV viewing $(A)$ and non-TV sedentary time $(B)$ within various MET (metabolic equivalent) index groups (MET index based on leisure time exercise and active commuting). $\mathrm{p}<0.0001$ for trend in TV time in all MET index groups, and $p<0.0001, p=0.0015$ and $p=0.035$ for trend in non-TV time in low, moderate and high MET index groups, respectively.

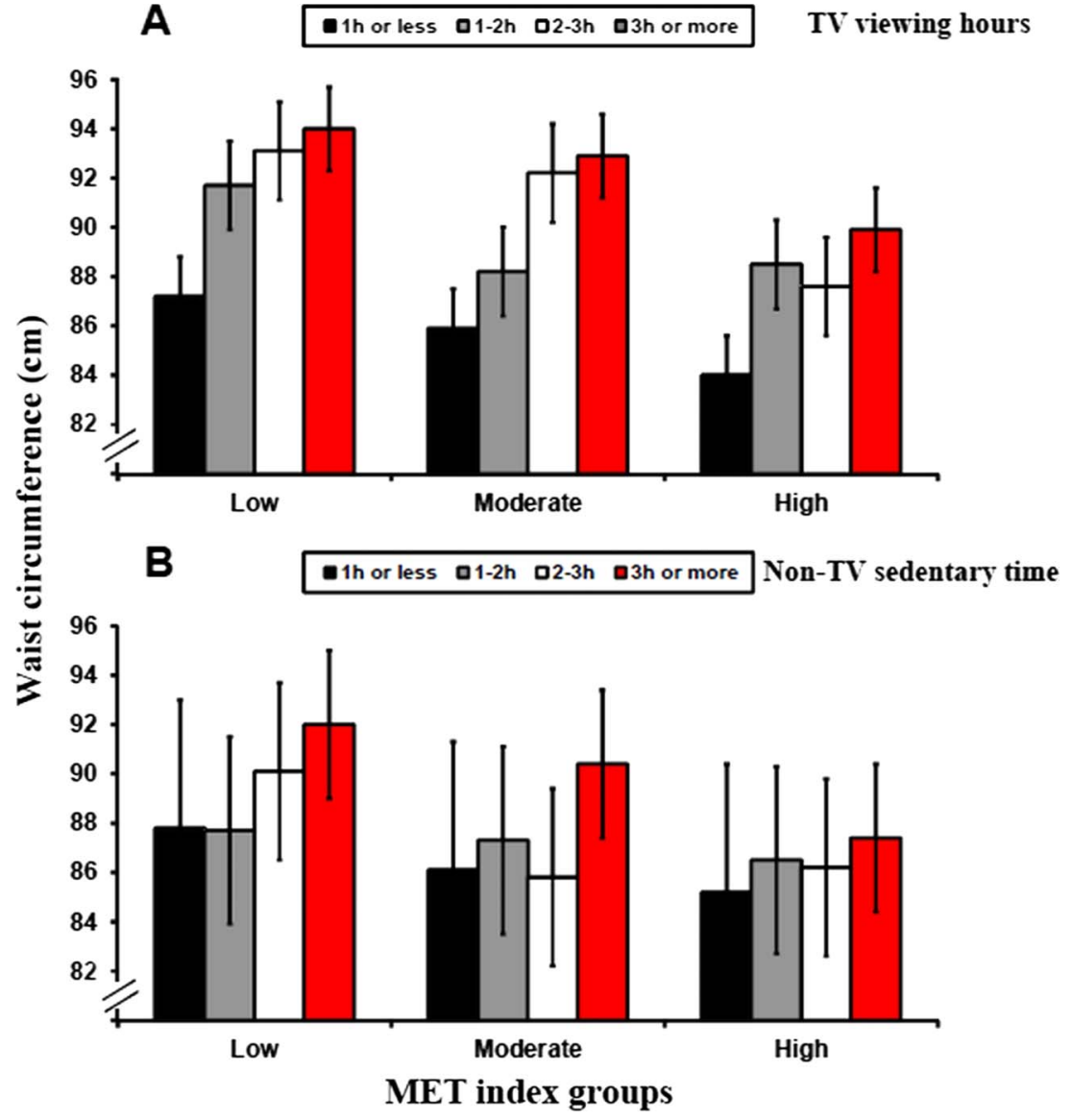

larger in individuals whose $\mathrm{TV}$ viewing time was $\geq 3 \mathrm{~h}$ compared with those $<1 \mathrm{~h} /$ day. In the moderate and high activity groups, the respective WC differences were 6.8 and $5.9 \mathrm{~cm}$, respectively.

\section{DISCUSSION}

In this cross-sectional study in a population-based sample of healthy adults, leisure-time sedentary behaviour, primarily TV viewing, was strongly associated with larger WC (and BMI) and risk of obesity. These relations remained highly significant, but were slightly diluted after controlling for a wide range of potential confounders associated with body adiposity, most markedly when adjusted for genetic and lifestyle confounders, and all dietary factors or individual food items that are associated with TV viewing. These observations thus further confirm the independent role of $\mathrm{TV}$ viewing as a risk factor for obesity, ${ }^{10}{ }^{11}$ but also suggest that the obesogenic effects of TV viewing are at least partly mediated

Table 6 Relative risks and 95\% Cls of obesity defined as large WC associated with TV viewing and non-TV sedentary time

\begin{tabular}{|c|c|c|}
\hline & Age-adjustment and sex-adjustment & Full model adjustment \\
\hline \multicolumn{3}{|l|}{ TV viewing time } \\
\hline$<1 \mathrm{~h}(\mathrm{~N}=644)$ & 1.00 & 1.00 \\
\hline$>1$ and $<2 \mathrm{~h}(\mathrm{~N}=544)$ & $1.64(1.29$ to $2.08 ; p=0.00005)$ & $1.60(1.26$ to $2.04 ; p=0.00014)$ \\
\hline$>2$ and $<3 \mathrm{~h}(\mathrm{~N}=201)$ & $1.83(1.35$ to $2.47 ; p=0.00008)$ & 1.62 (1.18 to $2.22 ; p=0.00297)$ \\
\hline$>3 \mathrm{~h}(\mathrm{~N}=70)$ & 1.91 (1.23 to $2.97 ; p=0.00379)$ & 1.63 ( 1.03 to $2.58 ; p=0.03762)$ \\
\hline \multicolumn{3}{|l|}{ Non-TV sedentary time } \\
\hline$<1 \mathrm{~h}(\mathrm{~N}=173)$ & 1.00 & 1.00 \\
\hline$>1$ and $<2 \mathrm{~h}(\mathrm{~N}=408)$ & $1.15(0.77$ to $1.73 ; p=0.49828)$ & $1.06(0.70$ to $1.60 ; p=0.78036)$ \\
\hline$>2$ and $<3 \mathrm{~h}(\mathrm{~N}=322)$ & 1.49 (0.99 to $2.23 ; p=0.05454)$ & $1.32(0.88$ to $1.98 ; p=0.18497)$ \\
\hline$>3 \mathrm{~h}(\mathrm{~N}=556)$ & $1.63(1.12$ to $2.38 ; p=0.01155)$ & 1.50 ( 1.02 to $2.21 ; p=0.03950)$ \\
\hline
\end{tabular}

WC $>88 \mathrm{~cm}$ in women and $>102 \mathrm{~cm}$ in men.

Full model=multivariable-adjustments for age, sex, genetic predisposition, leisure-time physical activity, energy intake, adherence to the recommended diet, and all diet items that are associated with TV viewing, sleep duration, socioeconomic status, smoking and alcohol consumption.

WC, waist circumference. 
by a non-prudent diet. Finally, since genetic predisposition to obesity was also weakly associated with sedentary time in men, these data are compatible with the hypothesis that reverse causation may also contribute to the association of sedentary time and adiposity.

Several studies have shown direct associations between TV viewing time and risk for obesity. ${ }^{9-11}{ }^{26-29}$ In line with these, we also found that TV viewing was strongly associated with BMI and $\mathrm{WC}$, as well as the risk of obesity. Individuals watching TV for more than $3 \mathrm{~h} /$ day compared with those viewing TV for less than $1 \mathrm{~h}$ /day had an almost twofold increased RR for obesity. These observations suggest that TV viewing is a potentially modifiable lifestyle factor that could be utilised in the prevention of obesity. One randomised controlled trial has been performed in adults where TV viewing time was reduced by $50 \%$ in overweight and obese adults over a 3-week period, and this study showed a significant increase in objectively measured energy expenditure resulting in decreased energy intake and BMI. $^{30}$ Another intervention study in children showed that a $50 \%$ reduction in TV and computer use produced significant reductions in BMI and energy intake, but no changes in physical activity. ${ }^{31}$ Similarly, another trial by Robinson ${ }^{32}$ demonstrated that the effects of reduced TV viewing on reducing obesity were mediated by changes in diet, not in activity. Moreover, a study by Cleland $e t a l^{33}$ suggested that the association between $\mathrm{TV}$ viewing and adiposity was partially explained by food and beverage consumption during TV viewing, but not by a reduction in overall leisure-time physical activity. Our observational data demonstrated that TV viewing was directly associated with WC in all individuals regardless of their physical activity level. In line with earlier studies, our results also suggest that the obesogenic effect of TV viewing may be partly mediated by energy intake and unhealthy eating habits. Altogether, these results add information and support the current key recommendations, which encourage the population not only to increase their physical activity and to adopt a healthy diet that corresponds to energy expenditure, but also to reduce the time spent in TV viewing to prevent the accumulation of excess body weight. ${ }^{22} 233435$

\section{Possible mechanisms of sedentary behaviour in increasing body adiposity}

Experimental studies in humans have demonstrated that an increase in sedentary behaviour is associated with reduced energy expenditure, development of an insulin resistance state, ${ }^{36}$ impaired insulin sensitivity and accumulation of abdominal fat. ${ }^{37}$ In addition to genetic predisposition, at least three mechanisms have been suggested to explain the accumulation of body fat due to sedentary behaviour. First, very low muscular activity during, for example, sitting may lead to a positive energy balance, since it is usually not compensated for by decreased energy intake. ${ }^{3}$ TV viewing is physically very passive and body metabolism during TV viewing corresponds closely to the resting metabolic rate. ${ }^{3-5}$ This may not be similar for all types of sedentary behaviour. Lack of non-exercise activity thermogenesis (low energy consuming activity, eg, standing and fidgeting while sitting) has also been shown to play a role in the accumulation of body fat, ${ }^{1638} 39$ and such condition typically develops during prolonged TV viewing. ${ }^{3-5} 40$

Second, sedentary behaviour has been associated with higher energy intake, which may confound or modify its association with adiposity. ${ }^{12}$ In our study, TV time viewing was associated with WC and BMI regardless of energy intake, although energy intake was also correlated with BMI and WC. Adjustment for energy intake and all dietary items that are associated with TV viewing also caused a moderate attenuation in the association between TV viewing and $\mathrm{WC}$, but the association remained highly significant. A part of the obesogenic effect of TV viewing may, however, be mediated by unhealthy dietary habits, and the true mediation may be somewhat larger due to the inaccuracies in capturing dietary habits in large population investigations. Dietary habits during TV viewing may thus differ from dietary habits during other activities or regular meals. Some other sedentary behaviours (eg, reading), on the other hand, may be associated with higher socioeconomic status, and healthier lifestyle choices, which protect from weight gain.

Third, it has been shown that sedentary behaviour would replace physical exercise and time spent in other physical activities and therefore could result in reduced energy expenditure and increased body weight. ${ }^{10}$ In the present study, we found no evidence for such relationship. In our data, there were no associations between sedentary behaviours and the indicators of physical activity. Moreover, the relations between sedentary behaviour and WC remained unchanged after adjustments for physical activity in multivariable models, and were observed in analysis across subgroups stratified by various physical activity levels. TV viewing, especially, was associated similarly and highly significantly with WC in all physical activity subcategories.

Finally, it has also been suggested that obese individuals might be more sedentary and otherwise physically less active because of their body weight and/or genetic predisposition. ${ }^{16}$ One study found that baseline markers of obesity (BMI, WC and fat mass) predicted adults' sedentary time at 5.6-year follow-up. ${ }^{41}$ We found that the genetic risk score for high $\mathrm{BMI}^{24}$ was associated with total sedentary time in men. The detected association was weak, however, and the adjustment for genetic risk did not dilute the association between sedentary behaviour and adiposity markers. This observation may reflect the possibility that overweight may lead to more sedentary behaviour, but these data are underpowered to make such a conclusion. Further studies are needed to explore the causal relationship between sedentary time and obesity, since plausible mechanisms that explain causality in both directions exist. Larger datasets are also required to explore whether lifestyle factors, such as 
sedentary behaviour, could modify or contribute to the relations between novel genetic risk factors and adiposity.

\section{Strengths and limitations}

The strength and novelty of our study is that we could take into consideration a wide range of confounders that could influence the relations between sedentary behaviour and adiposity. These include various types of physical activity, energy intake, detailed diet composition, alcohol consumption, smoking, socioeconomic status, sleep duration as well as novel genetic variants associated with increased BMI. Other strengths of our multicentre study are the relatively large number of participants and the precise measurements of WC, weight and height. The major limitation of our study is that, owing to the cross-sectional design, no statements can be made regarding the causalities of the observed associations. In addition, only information on the amount of leisure-time sedentary behaviour was available, but there were no data on the duration of individual sitting bouts or breaks during them. Owing to these inaccuracies in data collection, the observed relations are most likely weaker than in reality. The data on physical activities, sedentary behaviour and diet were collected with questionnaires, but not with objective methods. This may result in over-reporting of physical activity, and under-reporting of energy intake and inaccuracies in the quality of diet, ${ }^{42}{ }^{43}$ which is common in overweight and obese participants. ${ }^{19}{ }^{42-45}$ Information on diet was assessed using an FFQ which is widely used in nutritional epidemiology, but it has its limitations. Self-reporting relies on the participant's ability to remember and identify the foods consumed, and is prone to conscious or unconscious misreporting. The FFQ used in the present study has been validated among another, but sociodemographically similar, study group against 3-day food records, and has been found to give constantly higher consumption figures than the records. ${ }^{19}$ The most useful purpose of the FFQ is to rank individuals according to their average food consumption and nutrient intake, rather than by obtaining absolute values. All conclusions made in this study are based on the relative intakes on which FFQ is shown to be suitable. ${ }^{19}$ Finally, we did not apply the genetic risk score for high BMI in a formal Mendelian randomisation framework to infer causality between adiposity and sedentary time-therefore, the association between genetic score and sedentary time needs to be interpreted cautiously.

\section{Summary and conclusions}

In this cross-sectional analysis of a well-characterised, population-based sample of apparently healthy adults, TV viewing, but not other non-sedentary activities, was strongly associated with higher WC and BMI, as well as a higher risk of obesity. Importantly, this relation was not totally diluted after controlling for a wide range of potential confounders. There was already some indication that reduction of TV hours may induce weight reduction. If this relation turns out to be causal and mechanistically partly explained by adverse diet habits during TV watching, then interventions to reduce TV time with a simultaneous correction of concurrent eating habits could be adopted in obesity prevention programmes.

\section{Author affiliations}

${ }^{1}$ Research Centre of Applied and Preventive Cardiovascular Medicine, University of Turku, Turku, Finland

${ }^{2}$ Department of Physiology \& Health and Physical Activity, Paavo Nurmi Centre, University of Turku, Turku, Finland

${ }^{3}$ Department of Sport Sciences, University of Jyväskylä, Jyväskylä, Finland ${ }^{4}$ LIKES Research Center for Sport and Health Sciences, Jyväskylä, Finland ${ }^{5}$ Department of Medicine, University of Turku and Turku University Hospital, Turku, Finland

${ }^{6}$ Clinical Physiology and Nuclear Medicine, University of Turku and Turku University Hospital, Turku, Finland

${ }^{7}$ Department of Food and Environmental Sciences, University of Helsinki, Helsinki, Finland

${ }^{8}$ Department of Clinical Physiology, University of Tampere and Tampere University Hospital, Tampere, Finland

${ }^{9}$ Laboratory of Atherosclerosis Genetics, Department of Clinical Chemistry, University of Tampere, Tampere, Finland

Acknowledgements The expert technical assistance in data management and statistical analyses by Irina Lisinen and Ville Aalto are gratefully acknowledged.

Contributors $\mathrm{IH}, \mathrm{HH}$ and OTR wrote the paper, analysed the data and performed the statistical analyses. They were responsible for the final content of the manuscript. All authors contributed to the design of the research, read, edited and approved the final draft of the manuscript.

Funding The Young Finns Study has been financially supported by the Academy of Finland: grants 126925, 121584, 124282, 129378, 117797 and 41071; the Social Insurance Institution of Finland, Kuopio, Tampere and Turku University Hospital Medical Funds, the Juho Vainio Foundation, the Paavo Nurmi Foundation, the Finnish Foundation of Cardiovascular Research and Finnish Cultural Foundation, the Sigrid Juselius Foundation, the Tampere Tuberculosis Foundation and the Emil Aaltonen Foundation.

Competing interests None.

Patient consent Obtained.

Ethics approval The study was approved by the local ethics committees (Decision number 533/2006).

Provenance and peer review Not commissioned; externally peer reviewed.

Data sharing statement No additional data are available.

\section{REFERENCES}

1. Berrington DG, Hartge $P$, Cerhan JR, et al. Body-mass index and mortality among 1.46 million white adults. $N$ Engl $J$ Med 2010;363:2211-19.

2. Jacobs EJ, Newton CC, Wang Y, et al. Waist circumference and all-cause mortality in a large US cohort. Arch Intern Med 2010;170:1293-301.

3. Hamilton MT, Hamilton DG, Zderic TW. Role of low energy expenditure and sitting in obesity, metabolic syndrome, type 2 diabetes, and cardiovascular disease. Diabetes 2007;56:2655-67.

4. Katzmarzyk PT. Physical activity, sedentary behavior, and health: paradigm paralysis or paradigm shift? Diabetes 2010;59:2717-25.

5. Ainsworth BE, Haskell WL, Herrmann SD, et al. Compendium of physical activities: a second update of codes and MET values. Med Sci Sports Exerc 2011;43:1575-81.

6. Pettee KK, Ham SA, Macera CA, et al. The reliability of a survey question on television viewing and associations with health risk factors in US adults. Obesity (Silver Spring) 2009;17:487-93. 
7. Shields M, Tremblay MS. Screen time among Canadian adults: a profile. Health Rep 2008;19:31-43.

8. Shields M, Tremblay MS. Sedentary behaviour and obesity. Health Rep 2008;19:19-30.

9. Hu FB, Leitzmann MF, Stampfer MJ, et al. Physical activity and television watching in relation to risk for type 2 diabetes mellitus in men. Arch Intern Med 2001;161:1542-8.

10. Hu FB, Li TY, Colditz GA, et al. Television watching and other sedentary behaviors in relation to risk of obesity and type 2 diabetes mellitus in women. JAMA 2003;289:1785-91.

11. Mozaffarian D, Hao T, Rimm EB, et al. Changes in diet and lifestyle and long-term weight gain in women and men. $N$ Engl $J$ Med 2011;364:2392-404.

12. Pearson N, Biddle SJ. Sedentary behavior and dietary intake in children, adolescents, and adults a systematic review. Am J Prev Med 2011;41:178-88.

13. Elder CR, Gullion CM, Funk KL, et al. Impact of sleep, screen time, depression and stress on weight change in the intensive weight loss phase of the LIFE study. Int J Obes (Lond) 2011;36:86-92.

14. Bo S, Ciccone G, Durazzo M, et al. Contributors to the obesity and hyperglycemia epidemics. A prospective study in a population-based cohort. Int J Obes (Lond) 2011;35:1442-9.

15. Cappuccio FP, D'Elia L, Strazzullo $P$, et al. Sleep duration and all-cause mortality: a systematic review and meta-analysis of prospective studies. Sleep 2010;33:585-92.

16. Levine JA, Lanningham-Foster LM, McCrady SK, et al. Interindividual variation in posture allocation: possible role in human obesity. Science 2005;307:584-6.

17. Raitakari OT, Juonala M, Rönnemaa T, et al. Cohort profile: the cardiovascular risk in Young Finns Study. Int J Epidemiol 2008;37:1220-6.

18. Mansikkaniemi K, Juonala M, Taimela S, et al. Cross-sectional associations between physical activity and selected coronary heart disease risk factors in young adults. The Cardiovascular Risk in Young Finns Study. Ann Med 2011;44:733-44.

19. Paalanen L, Männisto S, Virtanen MJ, et al. Validity of a food frequency questionnaire varied by age and body mass index. J Clin Epidemiol 2006;59:994-1001.

20. Fineli. Finnish Food Composition Database. 7. 2007. Helsinki, Finland, the National Public Health Institute, Nutrition Unit.

21. National Nutrition Council. Finnish nutrition recommendations. Helsinki: Oy Edita, 2005

22. Lichtenstein AH, Appel LJ, Brands M, et al. Diet and lifestyle recommendations revision 2006: a scientific statement from the American Heart Association Nutrition Committee. Circulation 2006;114:82-96.

23. U.S. Department of Agriculture and U.S. Department of Health and Human Services. Dietary guidelines for Americans, 2010 7th edn. Washington, DC U.S. Government Printing Office, 2011.

24. Speliotes EK, Willer CJ, Berndt SI, et al. Association analyses of 249796 individuals reveal 18 new loci associated with body mass index. Nat Genet 2010;42:937-48.

25. Juonala M, Juhola J, Magnussen CG, et al. Childhood environmental and genetic predictors of adulthood obesity: the cardiovascular risk in young Finns study. J Clin Endocrinol Metab 2011;96:E1542-9.

26. Jakes RW, Day NE, Khaw KT, et al. Television viewing and low participation in vigorous recreation are independently associated with obesity and markers of cardiovascular disease risk: EPIC-Norfolk population-based study. Eur J Clin Nutr 2003:57:1089-96.

27. Aadahl M, Kjaer M, Jorgensen T. Influence of time spent on TV viewing and vigorous intensity physical activity on cardiovascula biomarkers. The Inter 99 study. Eur J Cardiovasc Prev Rehabil 2007;14:660-5.

28. Bertrais S, Beyeme-Ondoua JP, Czernichow S, et al. Sedentary behaviors, physical activity, and metabolic syndrome in middle-aged French subjects. Obes Res 2005;13:936-44.

29. Foster JA, Gore SA, West DS. Altering TV viewing habits: an unexplored strategy for adult obesity intervention? Am J Health Behav 2006;30:3-14

30. Otten JJ, Jones KE, Littenberg B, et al. Effects of television viewing reduction on energy intake and expenditure in overweight and obese adults: a randomized controlled trial. Arch Intern Med 2009;169:2109-15.

31. Epstein LH, Roemmich JN, Robinson JL, et al. A randomized trial of the effects of reducing television viewing and computer use on body mass index in young children. Arch Pediatr Adolesc Med 2008;162:239-45.

32. Robinson TN. Reducing children's television viewing to prevent obesity: a randomized controlled trial. JAMA 1999;282:1561-7.

33. Cleland VJ, Schmidt MD, Dwyer T, et al. Television viewing and abdominal obesity in young adults: is the association mediated by food and beverage consumption during viewing time or reduced leisure-time physical activity? Am J Clin Nutr 2008;87:1148-55

34. Artinian NT, Fletcher GF, Mozaffarian D, et al. Interventions to promote physical activity and dietary lifestyle changes for cardiovascular risk factor reduction in adults: a scientific statement from the American Heart Association. Circulation 2010;122:406-41.

35. Kumanyika SK, Obarzanek E, Stettler N, et al. Population-based prevention of obesity: the need for comprehensive promotion of healthful eating, physical activity, and energy balance: a scientific statement from American Heart Association Council on Epidemiology and Prevention, Interdisciplinary Committee for Prevention (formerly the expert panel on population and prevention science). Circulation 2008:118:428-64.

36. Stephens BR, Granados K, Zderic TW, et al. Effects of 1 day of inactivity on insulin action in healthy men and women: interaction with energy intake. Metabolism 2011;60:941-9.

37. Olsen RH, Krogh-Madsen $\mathrm{R}$, Thomsen $\mathrm{C}$, et al. Metabolic responses to reduced daily steps in healthy nonexercising men. JAMA 2008;299:1261-3.

38. Levine JA. Nonexercise activity thermogenesis-liberating the life-force. J Intern Med 2007;262:273-87.

39. Levine JA, Eberhardt NL, Jensen MD. Role of nonexercise activity thermogenesis in resistance to fat gain in humans. Science 1999:283:212-14.

40. Ainsworth BE, Haskell WL, Whitt MC, et al. Compendium of physical activities: an update of activity codes and MET intensities. Med Sci Sports Exerc 2000;32(9 Suppl):S498-504.

41. Ekelund $\mathrm{U}$, Brage $\mathrm{S}$, Besson $\mathrm{H}$, et al. Time spent being sedentary and weight gain in healthy adults: reverse or bidirectional causality? Am J Clin Nutr 2008;88:612-17.

42. Goris AH, Westerterp KR. Physical activity, fat intake and body fat. Physiol Behav 2008:94:164-8.

43. Jeffery RW, Harnack LJ. Evidence implicating eating as a primary driver for the obesity epidemic. Diabetes 2007:56:2673-6.

44. Pietiläinen $\mathrm{KH}$, Korkeila $\mathrm{M}$, Bogl $\mathrm{LH}$, et al. Inaccuracies in food and physical activity diaries of obese subjects: complementary evidence from doubly labeled water and co-twin assessments. Int J Obes (Lond) 2010;34:437-45.

45. Poslusna K, Ruprich J, De Vries JH, et al. Misreporting of energy and micronutrient intake estimated by food records and 24 hour recalls, control and adjustment methods in practice. $\mathrm{Br} J$ Nutr 2009;101(Suppl 2):S73-85. 